\title{
Low Caloric Intake Among Mexican - American High School Students May Suggest Food Insecurity and/or Insufficiency in the Household
}

\author{
Liset Leal-Vasquez, Tammy Wyatt, Ashley Love \\ University of Texas at San Antonio
}

\begin{abstract}
In the United States, health concerns such as food insecurity and obesity continue to rise among American households (Centers for Disease Control and Prevention, 2003). Poor dietary intake can result in poor health outcomes as well as negatively impact student academic performance (Sigman-Grant, 2003). Despite the growing health concerns among the youth, limited studies have examined the dietary patterns of the Mexican-American adolescent population. This study aims to fill that void by describing the dietary intake of predominantly Mexican-American adolescents 13-18 years of age $(n=532)$. The study design was cross-sectional and randomly selected high school participants based on their enrollment in physical education classes. Results of a one day 24-hour dietary recall showed both males and females in this study were below the national recommendations for total calories per day and reported poor eating behaviors. Further research is needed to investigate food insufficiency in this population who has high prevalence of overweight.
\end{abstract}

(c) 2007 Californian Journal of Health Promotion. All rights reserved.

Keywords: food insufficiency, food insecurity, obesity, Mexican-American adolescents

\section{Introduction}

In most recent national estimates, over 38 million people, including 13.9 million children have experienced food insecurity in 2004 (Holben, 2006). Food insecurity has been linked to poor dietary intake and nutritional status, poor health, increased risk for chronic diseases, poor psychological and cognitive function as well as poor student academic performance (Holben, 2006). Healthy People 2010 has declared a national goal to increase food security by $94 \%$ and to reduce hunger. The US Department of Agriculture's Community Food Security Initiative goal is to cut food insecurity in half by 2015 (Holben, 2006). Food insecurity is defined by national experts as the "limited or uncertain availability of nutritionally adequate and safe foods and limited or uncertain ability to acquire foods in a socially acceptable way" (Holben, 2006; Stang, Bayerl, \& Flatt, 2006). Food Insufficiency is defined as "an inadequate amount of food intake due to lack of money or resources” (Holben, 2006; Mazur, Marquis, \& Jensen, 2003).
Mexican-American households experience greater levels of food insecurity compared with the national average in the United States (Holben, 2006; Kaiser, Melgar-Quinonez, Lamp, Johns, Sutherlin \& Harwood, 2002). In fact the prevalence of food insecurity is higher in black (23.7\%) and in Hispanic households (21.7\%) than in households of other racial groups (Stang et al., 2006). Children living in Hispanic and African-American households headed by a single mother or father are at even greater risk for food insecurity than the national average. In recent reports $32 \%$ to $52 \%$ of children and adolescents living in poverty reported insufficient access to food on one or more days per month (Holben, 2006; Sigman-Grant, 2003).

Similarly, food insecurity and insufficiency were reported to be associated with low dietary quality in children especially older children (Holben, 2006). Holben (2006) also suggest that food insufficiency seems to be associated with a decreased consumption of dark green and other vegetables and an increased consumption of eggs. Moreover, Mexican-American school-age 
children living in households with food insecurity reported lower meat consumption (Holben, 2006). In Mexican-American households with preschool children food insecurity has been associated with limited varieties of most foods, especially fruit and vegetables (Holben, 2006). Among adolescents, Holben (2006) reports lower intake of fruits and vegetables is associated with food insecurity. Matheson, Varady and Killen (2002) found a significant decrease in energy intake and meat consumption as payday approached among fifth grade Hispanic children who were experiencing food insecurity.

Moreover, school-aged children that experienced food insufficiency had poor health status, more frequent stomachaches and more frequent headaches (Holben, 2006). Food insufficient children and teens ages six to eleven years were more likely to experience the following outcomes compared to their food sufficient counterparts: significantly lower arithmetic scores, more likely to have repeated a grade in school, have seen a psychologist, and have difficulty getting along with others. Similarly, food insufficient teens were found to be more likely to have seen a psychologist, been suspended from school, and have difficulty getting along with others than food sufficient teens (Alaimo, Olson, \& Frongillo, 2001).

Concurrently as the nation attempts to assist families in need of food to survive on a daily basis, childhood and adolescent obesity has become a pandemic in the United States (Casey, Simpson, Gossett, Bogle, Champagne, Connell et al., 2006). Obesity has been linked to poor eating behaviors and lack of physical activity among children and adolescent populations. The increase in obesity has been linked to type 2 diabetes, heart disease and other chronic illnesses, more commonly seen in MexicanAmericans and non-Hispanic Black populations (Lytle, 2002; Nicklas, Morales, Linares, Yang, Baranowski, Moor et al., 2004; Ogden, Flegal, Carroll, \& Johnson, 2002; Trevino, Mobley, Hernandez, Yin, Garcia \& Hale, 2004).

Various studies have suggested that food insecurity/insufficiency has a negative impact on health and overall quality of life in the children and adolescents. However, the question still remains whether food insecurity is related to a child's overweight status. According to Holben (2006), evidence does not support that food insecurity increases the risk of being overweight in childhood. Holben (2006) concludes that with severe lack of access, children seem to have a lower body weight. Conversely, Casey et al. (2006) found that adolescents aged 12-17 years, girls, white and non-Hispanic youth living in food-insecure households (with incomes less than $100 \%$ and greater than four times the federal poverty level) were more likely to demonstrate significant associations with being at risk for overweight. In the same study, associations with being at risk for overweight status were also found in children aged three to five years, boys, and Mexican American children (Casey et al., 2006).

Mazur, Marquis, Jensen (2003) also suggested that adolescents in a low-income household are twice as likely to be overweight or obese and four times more likely to be food insecure. Studies have also reported the paradox of food insufficiency and obesity among women. In 2003, Basiotis \& Lino found that women in food insufficient households had a significantly worse diet quality than women in food sufficient households. Food insufficient women had significantly lower healthy eating index scores for the consumption of vegetables, fruits and milk as well as overall food variety. Likewise, recent studies have found comparable associations between food insufficiency and prevalence of overweight among adult women (Basiotis \& Lino, 2003; Olsen, 1999; Townsend, Peerson, Love, Achterberg, \& Murphy, 2001). Townsend et al. (2001) reported mildly food insecure women were $30 \%$ more likely to be overweight than their food sufficient counterparts. Moreover, using body mass index scores, Basiotis \& Lino (2003) found a significantly higher percentage of women ages 19-55 within food insufficient households were overweight as compared to those in food sufficient households. According to Strauss and Knight (1999), the home environment is a critical factor in the development of childhood obesity. Their findings concluded that maternal 
obesity and low family incomes increase one's risk for developing obesity.

Children and adolescents require the essential daily nutrients to provide energy, build and repair body tissue and regulate body functions; however, recent national surveys suggest that this population is not consuming adequate amounts of foods or beverages that provide the essential nutrients needed for growth and development (Hale, 2000; Lytle, 2002). In adolescence, physical growth is rapid which creates a need for increased energy and nutrients. The health of adolescents is dependent on sufficient energy from food and nutrients to promote optimal physical, social, and cognitive growth and development. Adolescents with inadequate consumption of foods and beverages that provide energy and essential nutrients are at risk for poor health outcomes including obesity, iron deficiency anemia, and chronic diseases (Stang \& Bayerl, 2003).

The purpose of the study is to examine dietary intake among predominantly Mexican-American males and females 13-18 years of age. MexicanAmerican adolescents are at a higher risk for chronic illness and obesity (Lytle, 2002; Trevino et al., 2004). It is crucial that nutrition professionals gain a better understanding of the dietary intake among Mexican-American adolescents. This study aims to fill that void. Identifying essential nutrients consumed in excess and deficient in the adolescent's diet, based on national recommendations, will provide a framework for educators to develop prevention programs that target specific dietary needs. This study will also serve to gain a better understanding of the Mexican-American adolescent's diet in hopes of developing prevention programs that meet the needs of Mexican-American communities.

\section{Methods}

Study Participants

A total of 602 participants were assigned to participate in the 24-hour dietary recall collection. Only 532 participants (Female = 305; Male $=227$ ) from eight high schools were assessed for their dietary behaviors via a 24-hour dietary recall. Sixty-nine of the participants were absent on the day of the data collection and one participant refused to participate (see Figure 1). Participants were in the ninth $(n=392)$, tenth $(n=99)$ and eleventh grades $(n=41)$, who were enrolled in physical education classes. The mean age of the participants was 15.56 years with a standard deviation of 0.91 years. Of the 532 participants, $91.2 \% \quad(n=485)$ identified themselves to be of Hispanic origin, $7.0 \%$, $(n=37)$ Black, 1.5\% ( $n=8)$ White, .4\% $(n=2)$ Asian. Of those participants identifying as Hispanic, it is assumed that the participants are Mexican-American, specifically, due to the geographical location of the study which is South Texas. See Table 1 for specific participant demographics. The participating district serves over 56,000 students and is comprised of $90 \%$ economically disadvantaged students (Texas School Performance Review, 2001). In a previous study, within the same participating district, Trevino et al. (2004) reported that the annual income per household averaged \$11,000$\$ 12,000$, with the average of five living in the household. In addition, many of the households were headed by a single parent.

\section{Research Design}

This is a cross-sectional study. Participants were randomly selected to participate based on their enrollment in physical education classes. The lead physical education teacher was asked to select three class periods that would participate in the dietary collection. Each physical education class comprised of approximately sixty to eighty students; a maximum of thirty students were randomly chosen from each class, and were encouraged to participate due to limited funding. Participants were offered a healthy pre-packaged snack upon completion of the 24-hour dietary recall. Data collection was approved for use by the Institutional Review Board of the University of Texas at San Antonio and by the participating school district. 
Table 1

Total Number of Males and Females Participating in the Dietary Collection per Grade Level, Gender and Age

\begin{tabular}{|l|l|l|}
\hline Grade Level & \multicolumn{1}{|c|}{$\begin{array}{c}\text { Gender } \\
\text { Male (M) Female (F) }\end{array}$} & $\begin{array}{c}\text { Age in Years } \\
\text { Mean }(\mathbf{1 5 . 5 6} \text { yrs) and SD (0.91 yrs) }\end{array}$ \\
\hline 9th $(\mathrm{n}=392)$ & M (n=148) & 13 years $(\mathrm{n}=2)$ \\
\hline & $\mathrm{F}(\mathrm{n}=244)$ & 14 years $(\mathrm{n}=125)$ \\
\hline 10th $(\mathrm{n}=99)$ & M (n=58) & 15 years $(\mathrm{n}=236)$ \\
\hline & $\mathrm{F}(\mathrm{n}=41)$ & 16 years $(\mathrm{n}=130)$ \\
\hline 11th $(\mathrm{n}=41)$ & $M(\mathrm{n}=21)$ & 17 years $(\mathrm{n}=35)$ \\
\hline & $\mathrm{F}(\mathrm{n}=20)$ & 18 years $(\mathrm{n}=4)$ \\
\hline
\end{tabular}

\section{High Schools (13,000 adolescents) in a school district in South Central Texas}

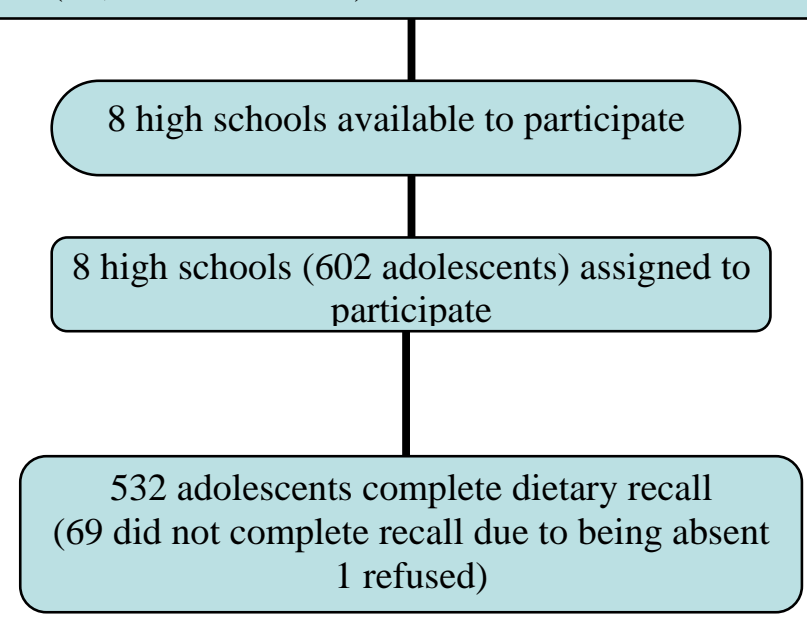

Figure 1

Study Sample

\section{Instrumentation}

The study's focus was to describe adolescent dietary intake, particularly within a predominantly Mexican-American population. To obtain this knowledge, interviewers utilized a 24-hour dietary recall booklet (see Appendix A). Each participant received a 24-hour dietary recall booklet and was asked to list and describe the foods and beverages consumed over the previous 24-hour period along with their name, grade and school they were attending. Analyses of diet recalls were performed using Nutritionist Pro Analysis Software (First Data Bank, 2004). The macronutrients of interest included: carbohydrate, protein, fat and fiber. The micronutrients of interest included: sodium, vitamin A, calcium and iron. Statistical analyses were performed with Statistical Package for Social Sciences 13.0 (SPSS, 2004). Descriptive statistics, including means with standard deviations (SD) were used to describe participant eating behaviors. Gender was entered as the covariate to the one-way analysis of variance. The significance level was set at $\mathrm{p}<0.05$.

Two interviewers were trained to complete the 24-hour dietary recall. Interviewers had an extensive background and training in nutrition and health and were professionally engaged in community work. The training included information on the purpose and history of 24- 
hour dietary recalls, how to use the standard dietary recall script, a visual picture of tools used, appropriate interviewing techniques and appropriate district documentation requirements (i.e., a child reports use of drugs or alcohol consumption). Interviewers were also trained on how to use a food recall booklet containing images of two- and three-dimensional food models of common measures (e.g., cups) and geometric food shapes (e.g., circles). The tool bag used for collecting a recall contained, a 24hour recall form, school menu, pencils, estimation tool book, ruler, two bowl sizes, two cup sizes, measuring cups/spoons, tablespoons, teaspoons and the most common size food models, such as pizza, and appropriate portion sized fruits and vegetables.

The 24-hour dietary recall used the multiplepass approach method in which each interviewer asked the respondent several times to search his or her memory to increase retrieval of the requested information (Nutrition Coordinating Center, University of Minnesota, 2006). The following information provides a brief description of a 24-hour dietary recall that uses the multiple pass approach: multiple pass 1 consisted of a quick list of foods and beverages consumed throughout the previous day. Other details also obtained included, time and location of each meal; multiple pass 2 consisted of a review of the quick list and another opportunity for the respondent to add to the list if needed; multiple pass 3 , allowed for the interviewer to refer back to the quick list and probe for specific details regarding food additions such as toppings added and the type of food, kind of food, name brand, method of preparation (fat used), kind of fat used, shape of food, and the actual amount eaten; multiple pass 4 included a final review of the recall in detail and provided the last opportunity to add to the list. If information was not remembered by the respondent, the interviewers recorded it as "unknown". The final question within the recall queried, "Do you think the amount of food you ate yesterday was, usual, more than usual or less than usual." The interviewer then asked whether the information provided was reliable, unable to recall more than one or more meals, or unreliable for other reasons. The last section allowed the interviewer to provide notes. All recalls were reviewed by the dietitian and entered into the computer by the program consultant.

\section{Results}

Table 2 shows the descriptive statistics of study participant's dietary intakes. Both males and females did not meet the national recommendations for total caloric needs for their respective age. According to the United States Department of Agriculture (2005), adolescent males should consume between 2000-3200 kcal per day, based on their age and activity level. Males in the study consumed an average kcal intake of 1695.90 per day. Likewise, females should consume 1800-2400 kcal per day (US Department of Agriculture, 2005). Females in the study consumed an average kcal intake of 1443.17 per day which is also below the national recommendation.

There was a significant difference in kcal consumed per day between gender groups $(\mathrm{F}=8.04, \quad \mathrm{p}<.005)$, with males consuming significantly more kcal per day than females (1695.90 kcal males and $1443.17 \mathrm{kcal}$ females; see Table 2). There were also significant differences in protein (grams) consumed between gender groups ( $F=10.97, \quad \mathrm{p}<.001)$. Males consumed 73.56 grams per day and females consumed 57.83 grams per day. Significant differences in fat (grams) consumed between gender groups $(\mathrm{F}=11.21, \mathrm{p}<.001)$ existed as well. Males consumed 64.63 grams of fat per day and females consumed 51.59 grams of fat per day. Significant differences in carbohydrates and fiber were not found between the gender groups.

There were significant differences in sodium consumption consumed between gender groups $(\mathrm{F}=7.564, \mathrm{p}<.006)$. Males consumed $2664.55 \mathrm{mg}$ of sodium per day and females consumed $2105.84 \mathrm{mg}$ of sodium per day. Moreover, significant differences in calcium consumption were found between gender groups $(F=4.908$, $\mathrm{p}<.027)$. Males consumed $674.25 \mathrm{mg}$ of calcium per day and females consumed $571.74 \mathrm{mg} /$ day. There were also significant differences in iron consumption between genders $(\mathrm{F}=10.085, \mathrm{p}<$ .002). Males consumed $12.82 \mathrm{mg}$ of iron per day 
and females consumed $10.37 \mathrm{mg} /$ day. Significant differences in Vitamin A consumption were not found between males and females. See Table 2 for comparison of macroand micronutrients by gender.

Table 2

Macronutrient and Micronutrient Values for 24-Hour Dietary Recall of Adolescents

\begin{tabular}{|l|c|c|c|c|}
\hline & Males (n=227) & Females (n=305) & F & P \\
\hline Kcal/day* & $1695.90(1113.523)$ & $1443.17(938.011)$ & 8.04 & .005 \\
\hline Carbohydrate (g) & $209.23(142.911)$ & $187.29(120.681)$ & 3.67 & .056 \\
\hline Protein* (g) & $73.56(59.637)$ & $57.83(49.727)$ & 10.97 & .001 \\
\hline Fat* (g) & $64.63(50.396)$ & $51.59(39.379)$ & 11.21 & .001 \\
\hline Fiber (g) & $14.46(14.085)$ & $12.51(12.008)$ & 2.936 & .087 \\
\hline Sodium* (mg) & $2664.55(3107.012)$ & $2105.84(1478.656)$ & 7.564 & .006 \\
\hline Vitamin A (IU) & $2201.14(1921.854)$ & $2756.92(4531.774)$ & 3.010 & .083 \\
\hline Calcium* (mg) & $674.25(597.168)$ & $571.74(469.833)$ & 4.908 & .027 \\
\hline Iron* (mg) & $12.82(9.164)$ & $10.37(8.559)$ & 10.085 & .002 \\
\hline
\end{tabular}

*significance $\mathrm{p}<.05$

Table 3 presents the percentage of kcal consumed from the 24-hour dietary recall collected. According to the U. S. Department of Agriculture (2005), adolescent males should consume between 2000-3200 kcal per day, based on their age and activity level. Males in the study consumed an average kcal intake of 1695.90 per day which is approximately 65\% (average between 2000-3200 kcal) below these recommendations. Females in the study consumed an average kcal intake of 1443.17 per day which is approximately 69\% (average between 1800-2400) below the recommendations provided by the U. S. Department of Agriculture. Male daily kcal distribution was $49 \%$ carbohydrate, $17 \%$ protein, and $34 \%$ fat while female daily kcal distribution was $52 \%$ carbohydrate, $16 \%$ of protein, and $32 \%$ of fat. The kcal distribution percentages fell within the recommended ranges; however, the total kcal consumed was below the national recommendations which may suggest food insufficiency.

Table 3

Percent Daily kcal for 24-Hour Dietary Recall of Adolescents

\begin{tabular}{|l|c|c|c|}
\hline & Male & Female & Recommendations \\
\hline Total kcal & 1695.90 & 1443.17 & $\begin{array}{r}\text { (m) } 2000-3200 \mathrm{kcal} \\
\text { (f) } 1800-2400 \mathrm{kcal}\end{array}$ \\
\hline \% Carbohydrate & $49 \%$ & $52 \%$ & $45-65 \%$ \\
\hline \% Protein & $17 \%$ & $16 \%$ & $10-35 \%$ \\
\hline \% Fat & $34 \%$ & $32 \%$ & $25-35 \%$ \\
\hline
\end{tabular}

Hale 2000; National Academy of Sciences, 2004

\section{Discussion}

In this study, significant differences among gender in total caloric consumption were noted.
The U. S. Department of Agriculture recommends caloric consumption for males and females aged 14-18 years to be 2000-3200 
calories and 1800-2400 calories per day, respectively, based on their age and activity level (see Table 4) (United States Department of Agriculture, 2005). Males in this study consumed an average intake of 1695.90 (1113.52) kcals and females consumed 1443.17 kcal (938.01) per day (see Tables 2 \& 3). Despite the findings of a higher caloric intake among males than females, this population did not meet national recommendations of total calories per day. Females in the study consumed an average calorie intake of $1443.17 \mathrm{kcal}$ per day which is approximately 69\% (average between 1800-2400) below the recommendations provided by the US Department of Agriculture (2005) (see Table 3). In this study, participants commonly reported consuming lunch through the National School Lunch Program and in many cases reported no breakfast or dinner consumption. In addition participants commonly reported consuming high calorie snacks, high consumption of soda and sugary beverages, minimal to no fruit or vegetable intake and high consumption of refined carbohydrates.

Table 4

MyPyramid Food Intake Pattern Calorie Levels*

\begin{tabular}{|l|c|c|c|c|c|c|}
\hline & & Male & & & Female & \\
\hline Age & Sedentary & Mod. Activity & Active & Sedentary & Mod. Activity & Active \\
\hline 13 & 2000 & 2200 & 2600 & 1600 & 2000 & 2200 \\
\hline 14 & 2200 & 2400 & 2800 & 1800 & 2000 & 2400 \\
\hline 15 & 2200 & 2600 & 3000 & 1800 & 2000 & 2400 \\
\hline 16 & 2400 & 2800 & 3200 & 1800 & 2000 & 2400 \\
\hline 17 & 2400 & 2800 & 3200 & 1800 & 2000 & 2400 \\
\hline 18 & 2400 & 2800 & 3200 & 1800 & 2000 & 2400 \\
\hline
\end{tabular}

* from MyPyramid Food Intake Pattern Calorie Levels, US Department of Agriculture (2005)

There were also significant differences among gender in protein consumption. The National Academy of Sciences, (2004) recommends males age nine to thirteen years consume 34 grams per day and males age 14-18 years consume 52 grams per day. Protein recommendations for females' age nine to thirteen years are 34 grams per day and for 1418 years of age 46 grams per day (see Table 5). In this study, males consumed 73.56 grams and females consumed 57.83 grams of protein (See Table 2 and Figure 3). According to Spear (2002), the average protein intake in adolescents is well above the recommendations in the United States. In this study, both genders exceeded the daily grams of protein intake (see Table 2). Participants consuming lunch through the National School Lunch Program are entitled to receive meals that are rich in protein. In the National School Lunch Program, federal nutrition requirements are set to provide one third of the Recommended Dietary Allowances
(RDAs) for protein, Vitamin A, Vitamin C, calcium, iron and calories. To meet this requirement, schools lunch programs commonly serve protein-rich foods such as, milk, meat, poultry, cheese, canned fish, dry beans, soy beans, peanut butter and eggs (USDA, 2004).

There were significant differences among gender in total fat consumption. In this study, males consumed 34\% fat (64.63 grams) and females consumed $32 \%$ fat (51.59 grams) (see Table 2 and Figure 2). National Academy of Sciences, (2004) recommends males and females consume a range of total fat between $25 \%-35 \%$ (See Table 3). Though both genders were within an acceptable percentage of fat intake on the days of the dietary collection, the quality of foods consumed is still in question. For participants reporting lunch consumption through the National School Lunch Program, there is some protection against eating foods that are high in saturated fat. The National School Lunch 
Program is required to meet the Dietary Guidelines for Americans, which recommends that no more than $30 \%$ of an individual's calories come from fat and less than $10 \%$ from saturated fat (USDA Food and Nutrition Services, 2004). Additional foods that are high in fat reported by the participants could also be dependent on what was available in the household during the 24-hour dietary recall collection. Families have reported more access to high fat fast foods when funds are more readily available (Kaiser et al., 2002).

The recommendation for fiber intake for males aged nine to thirteen years is 31 grams per day and for females 26 grams per day; males aged $14-18$ years is 38 grams per day and females 26 grams per day (see Table 6) (National Academy of Sciences, 2004). Both males and females in this study reported minimal to no fruit or vegetables intake. One participant did report eating whole grain bread on one occasion; however, other participants commonly reported a high intake of refined carbohydrates. Males, in this study, consumed 14.46 grams of fiber per day and females consumed 12.51 grams of fiber per day. Both males and females were below the national recommendation for fiber (see Table 2 and Figure 2). The role of dietary fiber has been linked to childhood weight management and the prevention of type 2 diabetes (Trevino et al.,
2004). However, despite its availability through the National School Lunch Program, many participants are not choosing to include fruits and vegetables into their daily diet. The National School Lunch Program is required to provide two or more servings of fruits or vegetables or both during meal service (USDA, 2004). According to the 2005, Youth Risk Behavior Surveillance, national statistics suggest that $20.1 \%$ of students had eaten fruits and vegetables greater than five times/day during the seven days preceding the survey. In the same survey, the overall prevalence of having eaten fruits and vegetables greater than five times/day was higher among male (21.4\%) than female (18.7\%) students and higher among black male (24.3\%) than black female $(19.9 \%)$ students. Lastly, in the same survey the overall prevalence of having eaten fruits and vegetables >5 times/day was higher among black (22.1\%) and Hispanic (23.2\%) than white (18.6\%) students; higher among Hispanic female (21.8\%) than white female (17.4\%) students; and higher among black male (24.3\%) and Hispanic male $(24.5 \%)$ than white male $(19.7 \%)$ students (Eaton, Kann, Kinchen, Ross, Hawkins, Harris et al., 2005). In the home environment, the consumption of dark green and other vegetable intake may decrease during times that the family may be experiencing food insecurity (Holben, 2006).

Table 5

Dietary Reference Intakes (DRIs): Recommended Intake for Individuals, Macronutrients and Acceptable Macronutrient Distribution Ranges

\begin{tabular}{|c|c|c|c|c|}
\hline Age & $\begin{array}{c}\text { Carbohydrate } \\
(\mathbf{g} / \mathbf{d})\end{array}$ & $\begin{array}{c}\text { Protein } \\
(\mathbf{g} / \mathbf{d})\end{array}$ & $\begin{array}{c}\text { Fat } \\
(\% \text { of energy) }\end{array}$ & $\begin{array}{c}\text { Fat } \\
(\mathbf{g} / \mathbf{d})\end{array}$ \\
\hline Males & & & & \\
\hline 9-13 years & 130 & 34 & $25-35$ & ND \\
\hline 14-18 years & 130 & 52 & $25-35$ & ND \\
\hline Females & & & & \\
\hline 9-13 years & 130 & 3446 & $25-35$ & ND \\
\hline 14-18 years & 130 & & $25-35$ & ND \\
\hline
\end{tabular}

Dietary Reference Intake for Energy, Carbohydrate, Fiber, Fat, Fatty Acids, Cholesterol, Protein, and Amino Acids (2002). National Academy of Sciences, 2004.

$\mathrm{ND}=$ Not Determinable 
Table 6

Dietary Reference Intakes (DRIs): Recommended Intake for Individuals

\begin{tabular}{|l|c|c|c|c|c|}
\hline \multicolumn{1}{|c|}{ Age } & $\begin{array}{c}\text { Sodium } \\
(\mathbf{g} / \mathbf{d})\end{array}$ & Vitamin A (ug/d) & Fiber (g/d) & Calcium (mg/d) & Iron (mg/d) \\
\hline Males & & & & & \\
\hline 9-13 years & 2.2 & 1700 & 31 & 1300 & 8 \\
\hline 14-18 years & 2.3 & 2800 & 38 & 1300 & 11 \\
\hline Females & & & & & \\
\hline 9-13 years & 2.2 & 1700 & 26 & 1300 & 8 \\
\hline 14-18 years & 2.3 & 2800 & 26 & 1300 & 15 \\
\hline
\end{tabular}

National Academy of Sciences, 2004

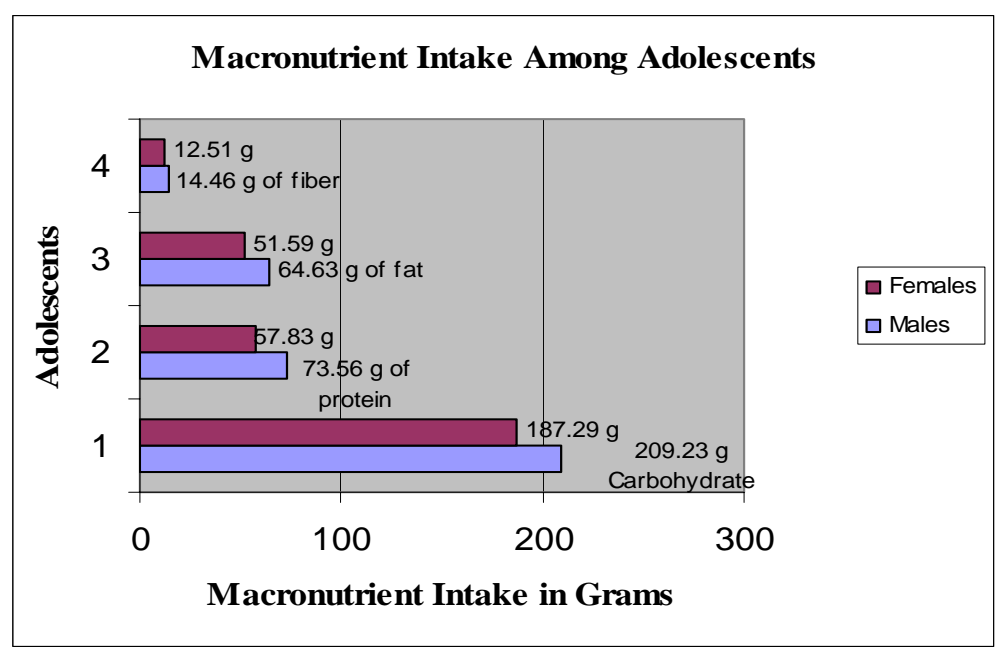

Figure 2

Macronutrient Intake in Adolescents

Carbohydrate, protein, and fat intake were above the recommendations for both genders, while fiber intake was below the recommendation (see Figure 2). Despite both genders exceeding the daily gram intake of carbohydrate, protein, fiber and fat, distribution of calories throughout the day was within acceptable ranges (see Table 3). The reported participant food intake was from a weekday 24-hour recall with the exception of one school reporting a weekend 24-hour recall. This weekend sample reported an average weekend dietary intake of 1516 calories verses a weekday consumption of 1845 calories. This finding may additionally support the belief that participants may be experiencing food insecurity and/or insufficiency in their household. In a study using the 12-item Radimer/Cornell scale to detect food insecurity in the household, Kaiser et al. (2002) discusses the complexity of food insecurity as a "managed process" in the household, which is believed to causes a sequence of responses as the food supplies decrease. Kaiser et al. (2002) continues to discuss the occurrences at the first level, which is considered of mild severity; during this time anxiety and concern about the household food supply begins to exist. As a result, the household makes adjustments that may affect the overall quality of the diet. At the adult level, which is considered of moderate severity, adults limit the quantity and quality of food consumed. At the last stage which is considered to be the most severe stage, the child feels the effects of the limited food supplies and experiences hunger. 
Characteristics that seem to appear as food insecurity increases in the household consist of less fruit and vegetable consumption, increased participation in food assistance programs and disordered eating (Kaiser et al., 2002).

In addition, this study found that males exceeded the sodium consumption per day (2664.55 mg per day) while females were within acceptable levels of sodium consumption per day (2105.84 mg day). Males consumed $674.25 \mathrm{mg}$ of calcium per day and females consumed $571.74 \mathrm{mg} /$ day. Males consumed $12.82 \mathrm{mg}$ of iron per day and females consumed $10.37 \mathrm{mg} /$ day. Calcium intake among both genders was below the national recommendations. Males meet the iron recommendations, while females did not (see Tables 2 and 6). The increase in soft drink consumption has been associated with a decrease in calcium intake among this age group (Spear, 2002). Participants in this study reported a high consumption on soda intake as well as sugary-type beverages which are not considered to be good sources of calcium. Possible conclusions for the increased sodium consumption among males could be attributed to the high intake of processed and snack typefoods reported such as fast food French fries, hamburgers, luncheon meats, snack crackers and chips.

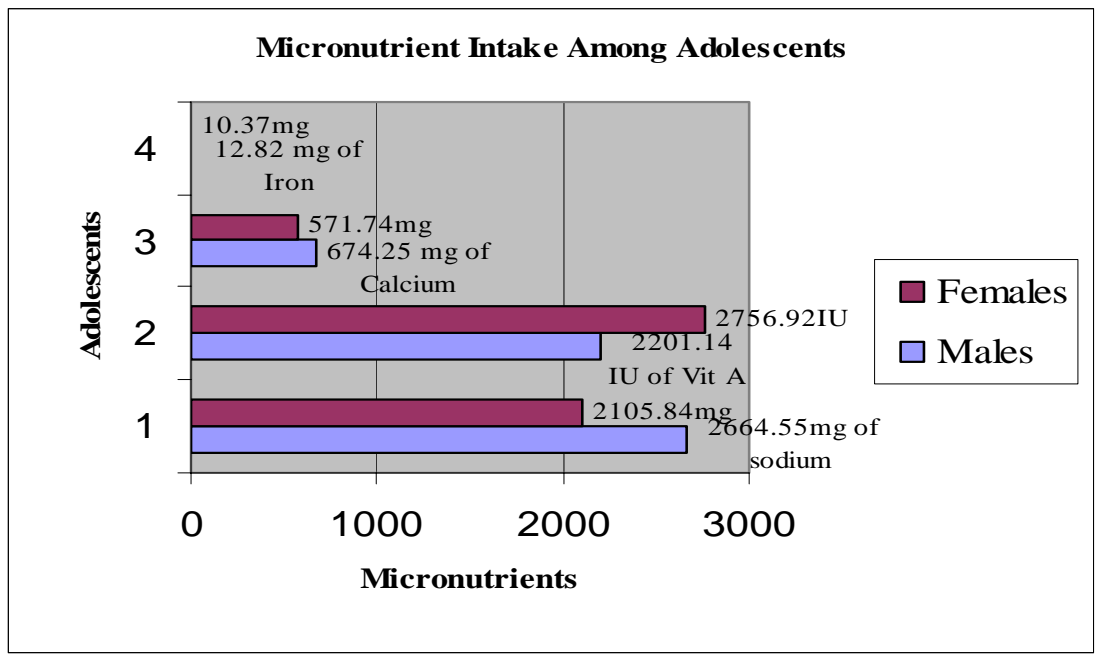

Figure 3

The 24-hour dietary recall completed by the participants asked if their consumption was usual, more than unusual or less than usual. Participants were asked to give an explanation based on their response. While only ten out of 532 participants provided qualitative comments regarding their food intake, these comments may suggest the existence of food insecurity and insufficiency as well as dietary inconsistencies.

The following statements were made by the participants in regard to their consumption:

usual consumption: "I was hungry.", "I eat various amounts of food during the day.", "Good food.”, "I ate good.”, "I don’t eat healthy. Well, at least I don’t take among Adolescents

think so, but I don't eat a lot either. I take vitamins for extra help for my body.”, "I am poor.", “I eat less now because they took my tonsils out and now I'm not used to eating a lot. My doctor said my stomach shrinked, cause I lost 20 pounds."

more than usual: "I ate a lot."

less than usual: "[It] varies from day to day, what I eat.", "I don't pick my own food at stores, my parents do."

Participants in this study reported low caloric intake and poor dietary behaviors, which may be a result of food insecurity and/or food insufficiency in the household. It has been noted that Mexican-American households experience 
greater levels of food insecurity compared with the national average in the United States (Holben, 2006; Kaiser et al., 2002). In the Mexican-American culture, many households survive on a low-income (Mazur et al., 2003). A low socioeconomic status has been consistently associated with poor child nutrition, health and development, along with food insufficiency (Mazur et al., 2003). Education, race, sex, ethnicity and literacy are associated with poverty and health disparities. The lack of being able to obtain appropriate health care and health insurance or the inability to understand the critical role of health behaviors in prevention of disease is commonly noted in this population (Harris, 2003; Mazur et al., 2003). Other contributing factors that affect the health of Mexican-Americans include food influences, food preferences and acculturation (Harris, 2003).

To better understand all the factors that contribute to eating behaviors among lowincome, Mexican-Americans, we first must understand the circumstances that may contribute to or compete with their dietary intake. Many possibilities have been associated with lack of food in the household, such as employee related problems, unemployment, low-paying jobs, high housing cost, poverty or lack of income, medical or healthcare costs, substance abuse, high utility costs, mental health issues, homelessness, reduced public benefits, gaining a household member and high child-care costs (Holben, 2006).

Food consumption in the Mexican-American culture depends on several factors such as income, education, urbanization, geographic region, and family customs and availability (Warrix, 1995). Families experiencing food insecurity have been found to use many coping skills to survive during difficult times. Coping skills include, eating a less varied diet, increased participation in federal food assistance programs or utilizing emergency food assistance from food pantries, emergency kitchens and shelters, adjusting the number of meals consumed and using low-cost energy-dense foods at times during financial hardships (Casey et al., 2006; Holben, 2006).
There are also several other possibilities to explain the inconsistency in eating behaviors among food insufficient households, such as overeating when food is available as well as purchasing cheaper, less nutritious foods that are energy-dense (Casey et al., 2006). Moreover, periods of both under- and over-consumption, episodic food shortages that cause physiologic adaptation of increased body fat, and an increased intake of less expensive foods that are higher in fat are associated with obesity (Centers for Disease Control and Prevention, 2003).

In this study, there are multiple reasons that could have contributed to the low caloric intake among participants, along with the possibility that participants did not have access to enough food, other possibilities include, dieting for weight loss, eating disorders, medical problems, or not hungry on the day of the collection. In this study, participants commonly reported consuming lunch through the National School Lunch Program, but in many cases reported no breakfast consumption through the National School Breakfast Program or dinner consumption.

Schools play an important role in promoting lifelong healthy eating and are considered to be an integral central location for the entire family to learn about good dietary behaviors and habits (Centers for Disease Control and Prevention, 1996). There is a great need to develop nutrition education programs for adolescents and their families that focus on improving dietary behaviors and nutrition knowledge (Hoelscher, Evan, Parcel \& Kelder, 2002). Nutrition programs that are behavioral-based are necessary to reduce the rates of obesity in the Mexican-American population. In addition, programs must be sensitive to address issues regarding food insecurity/insufficiency. Resources to local community organizations, shelters and school nutrition programs that assist in hunger efforts should be provided to parents and adolescents in this population. Currently the National School Lunch Program (NSLP) and School Breakfast Program (SBP) are required to provide a third of the Recommended Dietary Allowances (RDAs) for lunch and one fourth for breakfast (USDA Food and Nutrition Services, 
2004). In addition, meals should not exceed 30\% of energy from fat and $10 \%$ or less of saturated to meet Dietary Guidelines recommendations.

It has been shown that participation in food and nutrition programs provide a safety net for American children and adolescents at risk for poor nutritional intakes secondary to low socioeconomic status (Stang \& Bayerl, 2003). Federally funded food and nutrition programs have been shown to improve the intake of select nutrients and energy; to reduce rates of low birth weight, preterm birth, growth retardation, and iron deficiency anemia (Stang \& Bayerl, 2003).

Though additional future longitudinal studies are needed to determine the link between food insecurity to child overweight status; it is suggested that food insufficiency can have longterm effects in children which include the inability to establish life-long eating patterns, which can contribute to patterns of childhood, adolescent, and adult obesity (Mazur et al., 2003). Alarming findings of lack of food and consumption of poor quality foods among our youth requires a community of healthcare provides, schools, community leaders and legislation to come together and make this health crisis a national top priority.

\section{Implications for Research and Practice}

Obesity and chronic illness, such as type 2 diabetes among Mexican-American children and youth continue to increase as do the number of households experiencing food insecurity (Holben, 2006; Sigman-Grant, 2003; Trevino et al., 2004). A possible explanation for the relationship between food insecurity and obesity may include periods of both under- and over consumption, in which families may adopt unhealthy eating practices when food is plentiful or scarce which could compromise the nutritional quality of their diets (Sigman-Grant, 2003). In the United States, periods of food insecurity are most often reported towards the end of the food stamp cycle when food supplies are inadequate (Sigman-Grant, 2003). Study conclusions suggest that energy intakes among female and males adolescents do not meet the recommended energy intakes, which may be due to low economic status and food insufficiency.
Youth, eating behaviors may be a result of typical erratic and unpredictable eating patterns commonly seen in this population. Reported consumption among this group was mainly provided from the USDA National School Lunch program. Participants receive both breakfast and lunch at no charge. Based on the results of this study, it is recommended that nutrition education programs be culturally sensitive and appropriate as well as age appropriate to meet the needs MexicanAmerican adolescents. Nutrition programs must provide specific learning skills and knowledge that target behavior, such as how to improve fiber consumption through fruit and vegetables.

The limitations of this study include selfreported data which is subject to inaccurate reporting of dietary behaviors due to the use of recall. Secondly, the study used a convenient sample of participant which may not represent the entire adolescent population. In addition, the participants did not provide information on their socioeconomic status to fully assess whether they were experiencing food insufficiency. Lastly, the 24-hour dietary recall used within this study has not been tested for reliability or validity.

Future research is needed to better understand the relationship between obesity and food insufficiency among Mexican-American adolescents. Research and funding is also needed to improve fruit and vegetable consumption among adolescents of low income families. Collaboration among National School Lunch Programs and Fresh Produce Programs (FPP) would increase the availability of fresh fruit and vegetables for this population. The Fresh Produce Program (FPP), also known as the Volunteer Gleaning Program, provided by the local Food Bank, salvages and distributes fruits and vegetables not are going to be sold, to local agencies free of charge. Schools are in a key position to educate families on nutrition and prevention of chronic illness. Low-income families, need to receive nutrition education services at the locations, they are most likely to receive aid or services, such as the food bank, Women's Infants and Children (WIC), food stamps office, school district or local shelters. 
Schools must provide a healthy environment to reinforce good nutrition behaviors through coordinate school health programs, school health advisory councils, and nutrition and wellness polices. The National School Lunch and Breakfast Programs must continue to provide the best quality meals that meet macronutrients and micronutrients that are necessary for growth and development among adolescents. Parent programs should not only included nutrition education, but should provide critical resources and teach skills on how to obtain food security in the household.

\section{References}

Alaimo, K., Olson, C. Frongillo, E. (2001). Food insufficiency and American school-aged children's cognitive, academic, and psychosocial development. Pediatrics, 108, 44-53.

Basiotis, P., \& Lino, M. (2003). Food insufficiency and prevalence of overweight among adult women. Family Economics and Nutrition Review, 15(2), 55-57.

Casey, P., Simpson, P., Gossett, J., Bogle, M., Champagne, C., Connell, C. et al. (2006). The association of child and household food insecurity with childhood overweight status. Pediatrics, 118, 14061413.

Centers for Disease Control and Prevention. (1996). Guidelines for school health programs to promote lifelong healthy eating. Morbidity \& Mortality Weekly Report, 45(RR-9), 1-33. Retrieved May 1, 2007, from ftp://ftp.cdc.gov/pub/Publications/mmwr/rr/rr4509.pdf

Centers for Disease Control and Prevention. (2003). Self-reported concern about food security associated with obesity, Washington, 1995-1999. Morbidity \& Mortality Weekly Report, 52, 840-842. Retrieved May 1, 2007, from http://www.cdc.gov/mmwr/preview/mmwrhtml/mm5235a3.htm

Hale, D. (2000). Personal Health and Obesity and Weight Management. An invitation to health (4th ed.). Belmont, CA: Thomson Higher Education, pp. 89-143.

Harris, D. (2003). Effect of nutrition and physical training with Mexican Americans. Californian Journal of Health Promotion, 1(2), 176-182.

Hoelscher, D., Evan, A., Parcel, G., Kelder, S. (2002). Designing effective nutrition interventions for adolescents. Journal of the American Dietetic Association, 102, 52-63.

Holben, D. (2006). Position of the American Dietetic Association: Food insecurity and hunger in the United States. Journal of the American Dietetic Assocation, 106, 446-458.

Kaiser, L., Melgar-Quinonez, H., Lamp, C., Johns, M., Sutherlin, J., Harwood, J. (2002). Food security and nutritional outcomes of preschool-age Mexican-American children. Journal of the American Dietetic Association, 102, 924-929.

Lytle, L. (2002). Nutrition issues for Adolescents. Journal of the American Dietetic Association, 102, 812.

Matheson, D., Varady, J., and Killen, J. (2002). Household food security and nutritional status of Hispanic children in the fifth grade. The American Journal of Clinical Nutrition, 76, 210-217.

Mazur, R., Marquis, G., Jensen, H. (2003). Diet and food insufficiency among Hispanic Youths: acculturation and socioeconomic factors in the third National Health and Nutrition Examination Survey. The American Journal of Clinical Nutrition, 78, 1120-1127.

National Academy of Sciences. (2004). Dietary reference intakes. Retrieved October 25, 2005, from http://www.nap.edu

Nicklas, T., Morales, M., Linares, A., Yang, S., Baranowski, T., Moor, C., Berenson, G. (2004). Children's meal patterns have changed over a 21-year period: The Bogalusa heart study. Journal of the American Dietetic Association, 104, 753-761.

Nutrition Coordinating Center, University of Minnesota. (2006). Food and nutrient database and interview system descriptive. Retrieved March 18, 2007, from http://www.ncc.umn.edu/products/ndsrdescriptiveoverview.pdf

First Data Bank. (2004). Nutritionist pro analysis software. 
Ogden, C., Flegal, K., Carroll, M., and Johnson, C. (2002). Prevalence and trends in overweight among US children and adolescents, 1999-2000. The Journal of American Medical Association, 288, 1728-1732.

Olsen, C. M. (1999). Nutrition and health outcomes associated with food insecurity and hunger. Journal of Nutrition, 131, 521S-524S.

Sigman-Grant, M. (2003). Hungry and overweight the paradox of food insecurity in America. The Journal of Pediatric Nutrition and Development, 103, 12-28.

Spear, B. (2002). Adolescent growth and development. Journal of the American Dietetic Association, 102, S23-S29.

Stang, J., and Bayerl, T. (2003). Position of the American Dietetic Association: Child and adolescent food and nutrition programs. Journal of the American Dietetic Association, 103(7)887-893.

Statistical Package for Social Sciences, Inc. (2004). Statistical package for social sciences version 13.0. Chicago: Author.

Strauss, R., Knight, J. (1999).Influence of the Home Environment on the Development of Obesity in Children. Pediatrics, 103 (6)1-8.

Stang, J., Bayerl, C., Flatt, M. (2006). Position of the American Dietetic Association: Child and adolescent food and nutrition programs. Journal of the American Dietetic Association, 106, 14671475.

Texas School Performance Review. (2001). Retrieved March 18, 2007, from http://www.cpa.state.tx.us/tspr/sanantoniopr/

Trevino, R. P., Mobley, C., Hernandez, A. E., Yin, Z. Garcia, O., Hale, D. (2004). Impact of the Bienestar school-based diabetes mellitus prevention program on fasting capillary Glucose levels. Archives of Pediatrics \& Adolescent Medicine, 158, 911-917.

Townsend, M., Peerson, J., Love, B., Achterberg, C., \& Murphy, S. (2001). Food insecurity is positively related to overweight in women. The Journal of Nutrition, 131, 1738.

U. S. Department of Agriculture. (2004). Food and nutrition services. National School Lunch Program. Retrieved September 11, 2004, from http://www.fns.usda.gov/fns/

U. S. Department of Agriculture. (2005). Food intake pattern calorie levels. Retrieved July 9, 2005, from http://www.mypyramid.gov/professionals/index.html

Warrix, M. (1995). Cultural diversity: Eating in America, Mexican-American. Retrieved October 27, 2005, from http://ohioline.osu.edu/hyg-fact/5000/5255.html

\section{Acknowledgments}

This study was supported by the Carol White Physical Education Grant. The authors gratefully thank the participating school district, school coaches and participants for their support and contributions to the study. Findings, conclusions and recommendations detailed in this study are those of the authors and do not necessarily reflect the views of the Carol White Physical Education Funding Program. The data was primarily completed to fulfill the grant agreement. The data was also approved for use to complete a master's degree at the University of Texas in San Antonio in 2005. Thesis Committee Members: Thesis Committee Co-Chairs Tammy Jordan Wyatt, Ph.D., and Ashley Love, MPH., Dr. PH, and article reviewer Zenong Yin, Ph.D, Professor - Department Chair, Department of Health and Kinesiology, University of Texas at San Antonio, One UTSA Circle, San Antonio, Texas 78249, Ph.: 210-458-5650, Fax.: 210-458-5873, E-Mail: zenong.yin@utsa.edu.

$\underline{\text { Author Information }}$

Liset Leal-Vasquez MA, RD, LD*

Address: 9915 Dawn Trail

San Antonio, TX 78254

Ph.: 210-467-5294

E-Mail: Lisetlealvasquez@aol.com 
Tammy Jordan Wyatt, Ph.D.*

Assistant Professor

Department of Health and Kinesiology

University of Texas at San Antonio

One UTSA Circle

San Antonio, TX 78249

Ph.: 210-458-7285

Fax.: 210-458-5873

E-Mail: tammy.wyatt@utsa.edu

Ashley Love, MPH., Dr. PH.

Assistant Professor

Department of Health and Kinesiology

University of Texas at San Antonio

One UTSA Circle

San Antonio, TX 78249

Ph.: 210-458-6226

Fax.: 210-458-5873

E-Mail: ashley.love@utsa.edu

* corresponding author 


\section{Appendix A}

\section{Dietary Recall Booklet}
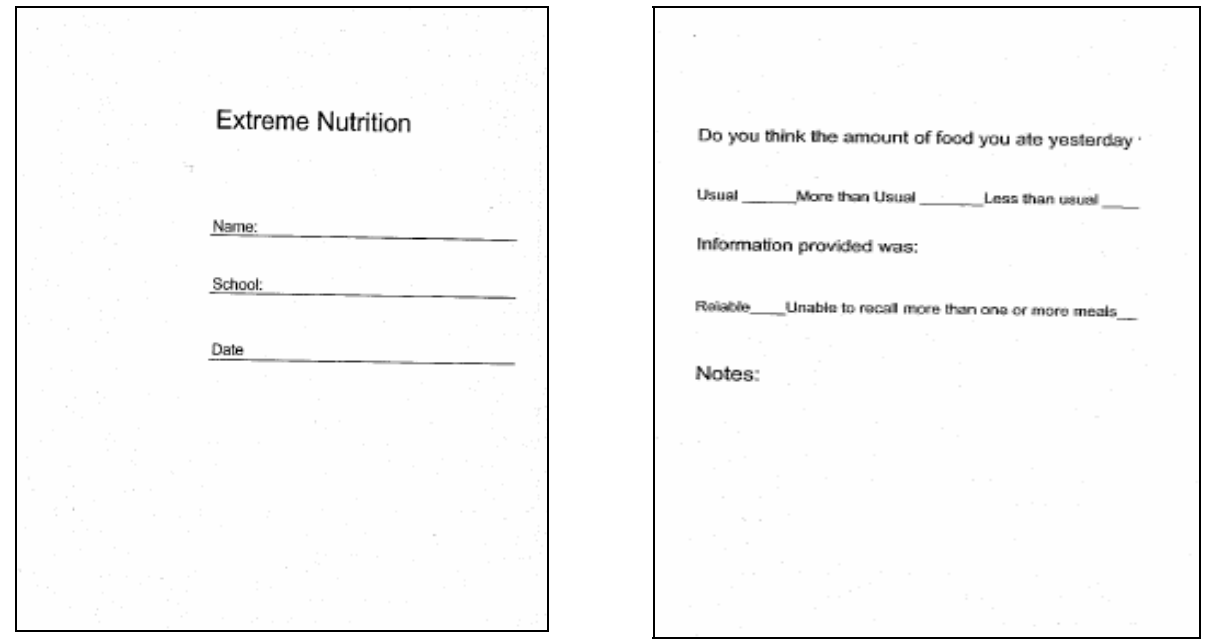

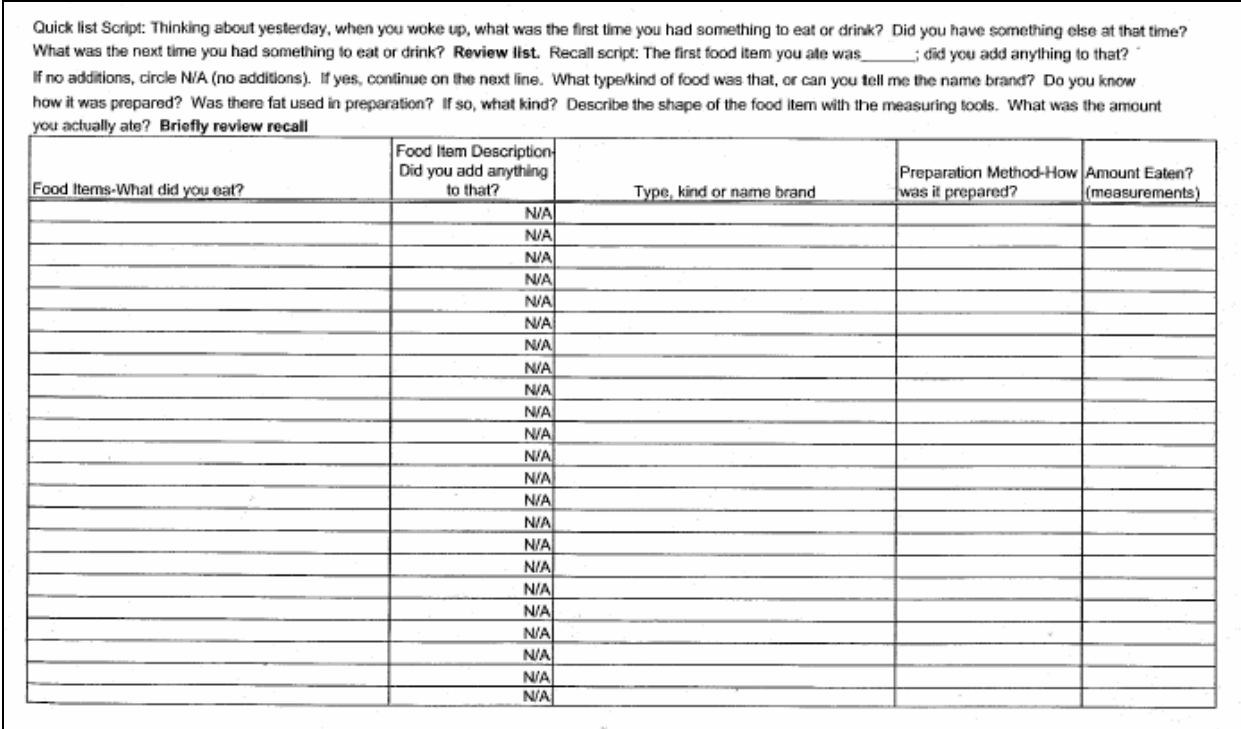

